\title{
Scale-Up of Biosynthesis Process of Bacterial Nanocellulose
}

\author{
Nadezhda A. Shavyrkina ${ }^{1,2}$, Vera V. Budaeva ${ }^{1, *} \mathbb{D}$, Ekaterina A. Skiba ${ }^{1}$, Galina F. Mironova ${ }^{1}$, Nikolay V. Bychin ${ }^{1}$, \\ Yulia A. Gismatulina ${ }^{1}$, Ekaterina I. Kashcheyeva ${ }^{1}$ (D), Anastasia E. Sitnikova ${ }^{1,2}$, Aleksei I. Shilov ${ }^{1,2}$, \\ Pavel S. Kuznetsov ${ }^{1,2}$ and Gennady V. Sakovich ${ }^{1}$
}

1 Laboratory of Bioconversion, Institute for Problems of Chemical and Energetic Technologies, Siberian Branch of the Russian Academy of Sciences (IPCET SB RAS), 659322 Biysk, Altai Krai, Russia; 32nadina@mail.ru (N.A.S.); eas08988@mail.ru (E.A.S.); yur_galina@mail.ru (G.F.M.); nbych@yandex.ru (N.V.B.); julia.gismatulina@mail.ru (Y.A.G.); makarova@ipcet.ru (E.I.K.); sitnikova97.97@mail.ru (A.E.S.); shilov_36@mail.ru (A.I.S.); black_heart98@mail.ru (P.S.K.); admin@ipcet.ru (G.V.S.)

2 Biysk Technological Institute, Polzunov Altai State Technical University, 659305 Biysk, Altai Krai, Russia

* Correspondence: budaeva@ipcet.ru

check for updates

Citation: Shavyrkina, N.A.; Budaeva, V.V.; Skiba, E.A.; Mironova, G.F.; Bychin, N.V.; Gismatulina, Y.A.; Kashcheyeva, E.I.; Sitnikova, A.E.; Shilov, A.I.; Kuznetsov, P.S.; et al. Scale-Up of Biosynthesis Process of Bacterial Nanocellulose. Polymers 2021, 13, 1920. https://doi.org/ $10.3390 /$ polym 13121920

Academic Editor: Fouad Erchiqui

Received: 18 May 2021

Accepted: 8 June 2021

Published: 9 June 2021

Publisher's Note: MDPI stays neutral with regard to jurisdictional claims in published maps and institutional affiliations.

Copyright: (c) 2021 by the authors. Licensee MDPI, Basel, Switzerland. This article is an open access article distributed under the terms and conditions of the Creative Commons Attribution (CC BY) license (https:// creativecommons.org/licenses/by/ $4.0 /)$.
Abstract: Bacterial nanocellulose (BNC) is a unique product of microbiological synthesis, having a lot of applications among which the most important is biomedicine. Objective complexities in scaling up the biosynthesis of BNC are associated with the nature of microbial producers for which $\mathrm{BNC}$ is not the target metabolite, therefore biosynthesis lasts long, with the BNC yield being small. Thus, the BNC scale-up problem has not yet been overcome. Here we performed biosynthesis of three scaled sheets of BNC (each having a surface area of $29,400 \mathrm{~cm}^{2}$, a container volume of $441 \mathrm{~L}$, and a nutrient medium volume of $260 \mathrm{~L}$ and characterized them. The static biosynthesis of BNC in a semisynthetic nutrient medium was scaled up using the Medusomyces gisevii Sa-12 symbiotic culture. The experiment was run in duplicate. The BNC pellicle was removed once from the nutrient medium in the first experiment and twice in the second experiment, in which case the inoculum and glucose were not additionally added to the medium. The resultant BNC sheets were characterized by scanning electron microscopy, capillary viscosimetry, infrared spectroscopy, thermomechanical and thermogravimetric analyses. When the nutrient medium was scaled up from 0.1 to $260 \mathrm{~L}$, the elastic modulus of BNC samples increased tenfold and the degree of polymerization 2.5-fold. Besides, we demonstrated that scaled BNC sheets could be removed at least twice from one volume of the nutrient medium, with the yield and quality of BNC remaining the same. Consequently, the world's largest BNC sheets $210 \mathrm{~cm}$ long and $140 \mathrm{~cm}$ wide, having a surface area of $29,400 \mathrm{~cm}^{2}$ each (weighing 16.24 to $17.04 \mathrm{~kg}$ ), have been obtained in which an adult with burns or vast wounds can easily be wrapped. The resultant sheets exhibit a typical architecture of cellulosic fibers that form a spatial 3D structure which refers to individual and extremely important characteristics of BNC. Here we thus demonstrated the scale-up of biosynthesis of BNC with improved properties, and this result was achieved by using the symbiotic culture.

Keywords: bacterial nanocellulose; biosynthesis scale-up; Medusomyces gisevii; BNC characterization

\section{Introduction}

Worldwide interest in bacterial nanocellulose (BNC) continues unabated and is due to its properties such as a 3D porous structure with nanosized fibers, high purity, high crystallinity and water-holding capacity, considerable mechanical strength and elasticity, high degree of polymerization, and excellent biocompatibility [1]. It is because of these properties that BNC has found a wide spectrum of applications, ranging from the food industry to medicine. BNC can be also used either as a component of food products or as a food packaging material [2]. But BNC is demanded most of all in medicine to improve health and save human lives. BNC is used as artificial skin, vascular grafts, dental 
implants, artificial bones and cartilages, a sorbent for targeted delivery of drugs, proteins and hormones, as well as for sorption and pinpoint use of stem cells [3].

While investigating properties of $\mathrm{BNC}$, such characteristics were discovered that make $\mathrm{BNC}$ an irreplaceable material in wound healing. The water-holding capacity of BNC and the nanostructured morphology of its fibers similar to the extracellular matrix protein, i.e., collagen, make BNC a highly promising material for cell immobilization $[4,5]$. These facilitate faster regenerative processes in wound healing [6,7]. The high biocompatibility of BNC mitigates risks of rejection and inflammatory response when placing a wound dressing and reduces the risk of fibrotic scarring [8,9]. Besides, it is because of the nanofiber network that BNC creates a physical barrier which prevents the wound site from bacterial infiltration and minimizes the risk of infections [10]. The extremely high water-holding capacity ( $1 \mathrm{~g}$ dry BNC is capable of holding $99 \mathrm{~g}$ water) keeps a moist environment around the wound, preventing it from drying out, and fosters outflow of wound exudate [11-13]. The biodegradation property of BNC can be exploited to make dressings that will need no removal, that is, no painful feelings when the wound is undressed, which is topical for chronic wounds $[14,15]$.

All those properties allow BNC to be reckoned as a revolutionary wound-healing material, which makes research on BNC production technology highly relevant and important. The key difficulty that restrains adoption of BNC as a massive wound-healing dressing is the issue of its production scale-up. The large pharma Johnson \& Johnson attempted to commercialize BC as far back as 1980s, particularly as a dressing to accelerate wound healing, but details of any clinical trials have never been made public and the commercial product has not been produced $[16,17]$. In the 1990s, another study into the commercial production of BNC was undertaken by a series of large Japanese companies and government-owned organizations for the purpose of massive production of BNC [18]. About $\$ 45$ billion was expended for this research, resulting in numerous patents and publications, but no successful commercial production was subsequently established. In the 1990s, basic research on BNC biosynthesis was also pursued in Poland, whereby an effective Gluconacetobacter strain was discovered that is capable of producing cellulose in more economical nutrient media [19]. Thus, the focus of scientific research has turned towards discovering new microbial producers of BNC that would allow the improvement in productivity of BNC biosynthesis.

A 2016 book by Gama [1] discusses a project of scaled production of bacterial cellulose as a hydrogel, with a capacity of more than 500 tons a year, and outlines economic cost estimations for this production: with a final cost of $1 \mathrm{~kg}$ BNC hydrogel at $\$ 25$, the payback period of investments in production is expected to be 4 years.

The objective complexity in scaling up the BNC biosynthesis process [20] stems from the nature of microbial producers for which BNC is not the target metabolite, therefore biosynthesis takes a long time and the yield of $\mathrm{BNC}$ is not high: the biosynthesis time for static culture is 5 to 20 days, with the yield not exceeding $8 \mathrm{~g} / \mathrm{L}$ [21]. Nonetheless, the high value of $\mathrm{BNC}$ justifies great costs for its production.

Works on enhancing the BNC yield include the following directions: a search for and genetic construction of new high-productivity microbial producers [1,5,21,22]; design of new technological approaches to cultivation $[5,20,21,23]$; and a quest for alternative and cheap raw sources [5,24-29]. Sharma [5] stresses that the high capital investment together with high operating costs is the major constraint towards commercialization of BNC at a reasonable cost.

Among the promising directions in boosting the productivity of the BNC production process is upgrading fermentation equipment and, in this case, a question arises about the way how to organize cultivation, whether it be stationary or dynamic, because microbial producers of BNC are obligate aerobes? Choi et al. [30] reported a pilot-scale production under agitated conditions in a 50-L modified bubble column bioreactor of airlift type using saccharified food waste as the feedstock. Stirred-tank bioreactors serve as a tool to scale up production and lead to higher production yields of BNC [31]. However, the index of 
crystallinity of such a cellulose is as low as $37 \%$. Besides, cellulose obtained under stirred conditions has limitations in use.

At the same time, agitation does not allow homogeneous, quality BNC films to be obtained. This results in a fibrous or granulated material [32]. The yield of the resultant BNC is usually lower than that in static culture because the shear stress promotes mutation of bacteria into strains that do not produce cellulose [33]. Kralisch et al. [34] reported a 180-L reactor with horizontal lift (HoLiR). It combines both strategies, the static and agitated culture, and provides semi-continuous cultivation and harvesting of flat nonwoven materials and BNC films. Those authors note that the semi-continuous biosynthesis technique and process scale-up decrease production costs appreciably.

Proceeding from the set objective of producing a bacterial cellulose sheet with such dimensions and high strength behavior so that an adult having vast burns could be wrapped in it, we elected to perform a scaled cultivation by the static method that gives access to an unbroken structure of cellulosic fibers.

In the present study, we performed biosynthesis of three scaled sheets of BNC (each having a surface area of $29,400 \mathrm{~cm}^{2}$, a container volume of $441 \mathrm{~L}$, and a nutrient medium volume of $260 \mathrm{~L}$ ) and investigated their properties. To the best of our knowledge, this is the largest-scale stationary cultivation in the world practice.

\section{Materials and Methods}

\subsection{Biosynthesis of BNC}

\subsubsection{Microbial Producer of BNC}

The Medusomyces gisevii Sa-12 symbiotic culture acquired from the All-Russian National Collection of Industrial Microorganisms (Scientific Center 'Kurchatov Institute', Research Institute for Genetics and Selection of Industrial Microorganisms, Moscow, Russia) was used herein as the microbial producer. The producer has advantages of being tolerant to the foreign microflora and stably producing BNC. The required amount of the inoculum $(26 \mathrm{~L})$ was prepared from the lab-grown culture in a pilot-scale fermentor. For the inoculum preparation, we used a semisynthetic nutrient medium consisting of glucose $(20 \mathrm{~g} / \mathrm{L})$ and black tea extract $(5 \mathrm{~g} / \mathrm{L})$ [35]; the culture purity was monitored by microscopy.

\subsubsection{Preparation of Nutrient Medium (260 L) for Scaled Cultivation}

A 234-L nutrient medium was prepared in a stainless-steel stirred reactor at the pilot production site of the IPCET SB RAS. For scaled cultivation, we used a semisynthetic medium with the same composition as that used for the inoculum preparation: $20 \mathrm{~L} / \mathrm{g}$ glucose (CAS No. 219 5996-10-1, OOO PromSintez, Chapayevsk city, Russia) and $5 \mathrm{~g} / \mathrm{L}$ black tea extract. Ready-to-use water was poured into the reactor and heated to boil; weighed portions of glucose and black tea were added to the boiling water, and the reactor heating was tuned off. The medium was held for $30 \mathrm{~min}$, then filtered and put into a biosynthesis container.

The biosynthesis container was a stainless-steel vessel of $210 \mathrm{~cm}$ in length, $140 \mathrm{~cm}$ in width and $15 \mathrm{~cm}$ in height, with a total volume of $441 \mathrm{~L}$. On scaled cultivation, the container was filled with the nutrient medium to $60 \%$ of its volume, more specifically to $260 \mathrm{~L}$. The container had these dimensions because the idea was to produce a BNC sheet having such a size so that, if necessary, an adult could be wrapped in it.

\subsubsection{Biosynthesis of BNC Sheet}

Biosynthesis of BNC sheets was performed subject to the following conditions: no agitation and temperature and humidity in the room were maintained automatically at $27^{\circ} \mathrm{C}$ and $85 \%$, which is optimum for the microbial producer used. After being filled with the water and inoculum, the container was covered with a sterile non-woven material (Megaspan Agro light-stabilized covering fabric, Fuleren Factory, Barnaul city, Russia), which provided oxygen supply to the microbial producer and protected the container from potential contaminants during biosynthesis. 
Biosynthesis of large-scale BNC sheets was run in the following manner. The first cultivation was continued for 14 days, then the sheet (designated as Sheet 1 ) was taken out of the culture medium surface and washed, and the remaining nutrient medium was not used further. In the second experiment, the container was filled with a nutrient medium, the inoculum was added, the biosynthesis was continued under the aforesaid conditions for 14 days, and then the sheet was taken out (designated as Sheet 2/1) and washed, and the remaining nutrient medium was left for further biosynthesis for another 14 days; a fresh inoculum and a fresh portion of glucose were not injected. After a 14-day cultivation, one more sheet (designated as Sheet 2/2) was taken out and washed as well.

The concentration of glucose in the culture medium was analyzed by a UNICO UV2804 spectrophotometer (United Products \& Instruments Inc., Dayton, NJ, USA) using 3,5-dinitrosalycilic acid (Panreac, Barcelona, Spain) as reagent [36]. The active acidity of the medium was measured potentiometrically by an I-160MI ion meter (OOO Izmeritelnaya Tekhnika, Moscow, Russia).

\subsubsection{Removal and Washing of BNC Sheet}

After the biosynthesis process was complete, the sheets were taken out of the growth medium surface and washed; the washing routine is detailed elsewhere [35]. Figure 1 displays photographs of the BNC sheet when it was in the biosynthesis container and when removed from the nutrient medium surface.

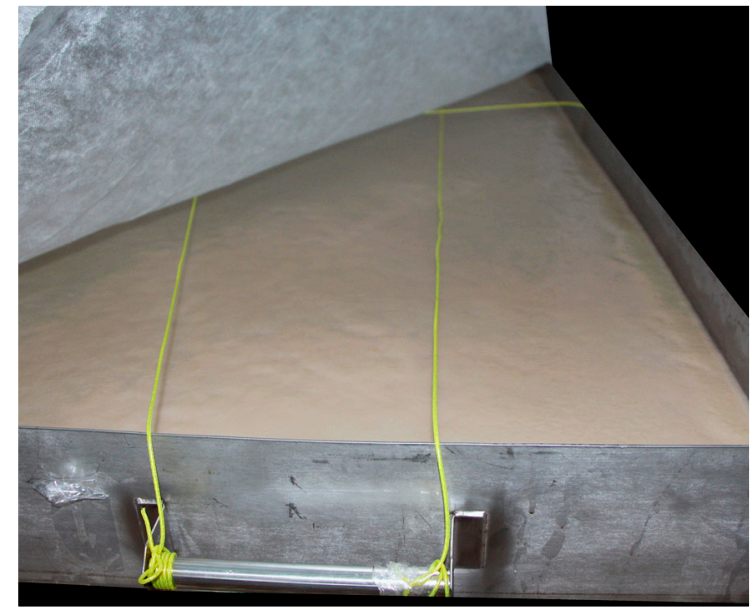

(a)

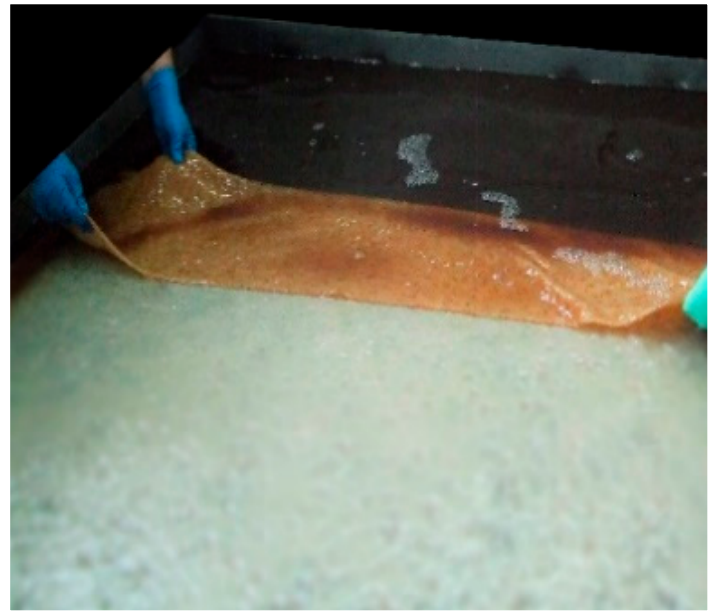

(b)

Figure 1. Biosynthesis of BNC sheets: (a) BNC sheet in the biosynthesis container 14 days post-cultivation and (b) removal of BNC sheet from the nutrient medium surface.

BNC was washed at room temperature by successively immersing the BNC sheets into a 15-fold volume of a $\%$ NaOH solution (CAS No. 1310-73-2, OAO Kaustik, Volgograd, Russia), then into distilled water (until the gel-films turned white), next into a $0.1 \% \mathrm{HCl}$ solution (CAS No. 7647-01-0, AO LenReaktiv, Saint-Petersburg, Russia), and finally into distilled water (until neutral wash waters). As the BNC sheets had a heavy weight and a great thickness, the washing took long and required that wash waters be replaced by fresh reagent solutions 5-6 times in each case. Photographs of the BNC sheets before and after washing are shown in Figure 2.

After the washing was complete and the sheets were held on a kapron sieve until the water completely ran off, the sheets were weighed on a platform electronic balance (ZAO MASSA-K, Saint-Petersburg, Russia). 


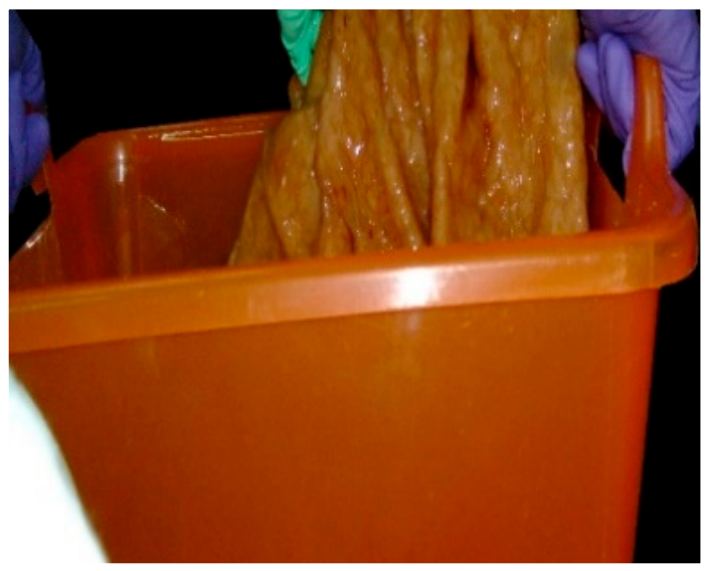

(a)

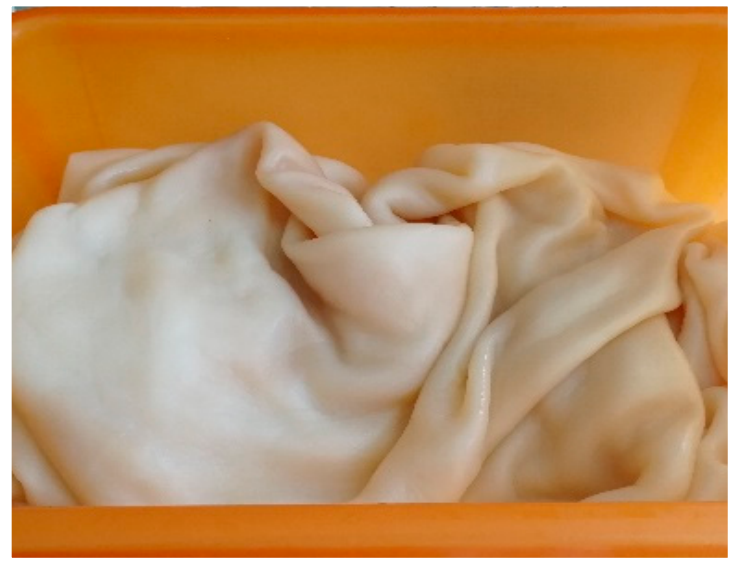

(b)

Figure 2. Washing of BNC sheets: (a) unwashed BNC sheet and (b) washed BNC sheet.

\subsubsection{Moisture Measurement of BNC Sheets}

To measure the moisture content, samples of the $\mathrm{BC}$ pellicles washed off of cell debris and weighing $1.0 \mathrm{~g}$ to an accuracy of $0.002 \mathrm{~g}$ were dried at $120^{\circ} \mathrm{C}$ to constant weight and then weighed again. The moisture was estimated as the difference in weight of the sample before and after drying [37].

\subsubsection{Calculation of BNC Yield}

The yield of BNC (\%) was calculated by Equation (1):

$$
\eta=\frac{m_{B N C}}{C_{g} \cdot V \cdot 0.9} \cdot 100
$$

where $\eta$ is the BNC yield, \%; $m_{B N C}$ is the BNC sample weight on an oven-dry basis $(\mathrm{g}) ; C_{g}$ is the glucose concentration in the medium $(\mathrm{g} / \mathrm{L}) ; V$ is the nutrient medium volume $(\mathrm{L})$; and 0.9 is the conversion factor attributed to the water molecule detachment when glucose is polymerized into cellulose. The yield was calculated as reported [38].

In calculating the yield of the second BNC sheet taken out of the same nutrient medium (designated as Sheet $2 / 2$ in the experiment), we used the same formula but took into account the altered parameters such as glucose concentration and nutrient medium volume because some of the medium (including glucose) had been consumed for biosynthesis of the first sheet designated as Sheet 2/1.

\subsubsection{Structural Characterization of BNC}

The surface morphology of BNC fibers was studied by scanning electron microscopy (SEM) on a JSM-840 scanning electron microscope (JEOL Ltd., Tokyo, Japan) after sputtering a Pt layer 1-5 nm thick. The BNC sample having dimensions of $5 \mathrm{~cm} \times 5 \mathrm{~cm}$ was preliminarily held in aqueous ethanol solutions at different concentrations of $25 \%, 50 \%, 75 \%$ and $90 \%$ for $30 \mathrm{~min}$ in four steps for partial dehydration of the BNC sample; afterwards, the BNC sample was freeze-dried in an HR7000-M lyophilizer (Harvest Right, LLC, Salt Lake City, UT, USA).

Scanning electron microscopy (SEM) of freeze-dried BNC samples pre-dehydrated with ethanol was done using a JSM-840 microscope (JEOL Ltd., Tokyo, Japan) with a Link-860 series II X-ray microanalyzer. Repeats information given above

\subsubsection{Measurement of Degree of Polymerization}

The BNC sample required for analysis was preliminarily freeze-dried.The degree of polymerization of BNC samples was measured by the viscometric method [39] using cadoxene as solvent (ethylenediamine, CAS No. 107-15-3, AO LenReaktiv; cadmium oxide, 
CAS No. 1306-19-0, AO LenReaktiv). The capillary viscosimetry was performed on a VPZh3 viscometer with a capillary diameter of $0.92 \mathrm{~mm}$ (Ekroskhim, Saint-Petersburg, Russia).

\subsubsection{Infrared Spectroscopy}

The BNC sample required for analysis was preliminarily freeze-dried. Infrared spectroscopy was performed on an Infralum FT-801 FTIR spectrophotometer (OOO NPF Lumex Sibir, Novosibirsk, Russia) at $4000-500 \mathrm{~cm}^{-1}$ in $\mathrm{KBr}$ pellets.

\subsubsection{Thermomechanical Analysis of BNC Samples}

The BNC sample required for analysis was preliminarily freeze-dried. The strength of BNC was measured on a DTG-60 thermomechanical analyzer (Shimadzu, Kyoto, Japan) whereby the test sample was stretched at a rate of $5.0 \mathrm{~g} / \mathrm{min}$ from $0.0 \mathrm{~g}$ to a maximum load of $400.0 \mathrm{~g}$ until failure; the test temperature was $23.0^{\circ} \mathrm{C}$.

The thickness of BNC samples was measured by a ICh-10 I-class dial indicator thickness gauge (Kirov factory 'Krasny Instrumentalshchik', Kirov city, Russia). Thermomechanical analysis of the samples to measure the strength behavior was performed on a Shimadzu TMA-60 thermomechanical instrument. The test samples were stretched at a rate of $5.0 \mathrm{~g} / \mathrm{min}$ to a maximum load of $500 \mathrm{~g}$ at room temperature.

The elastic modulus was estimated by Equation (2):

$$
E=\frac{\sigma_{s x}}{\left(\frac{\varepsilon_{s x}}{100}\right)}
$$

where $E$ is the modulus of longitudinal elasticity, $\mathrm{MPa} ; \sigma_{s x}$ is the conventional yield limit, $\mathrm{MPa} ; \varepsilon_{s x}$ is the relative elongation at yield, $\%$.

\subsubsection{Thermogravimetric Analysis of BNC Samples}

The BNC sample required for analysis was preliminarily freeze-dried. Thermogravimetric analysis was performed on a Shimadzu DTG-60 thermogravimetric analyzer. The test conditions were as follows: the test sample was heated at a rate of $10^{\circ} \mathrm{C} / \mathrm{min}$ to a maximum temperature of $600{ }^{\circ} \mathrm{C}$ in nitrogen environment at a flow rate of $40 \mathrm{~mL} / \mathrm{min}$. The sample weight was $p=6.0-6.5 \mathrm{mg}$. The analyses were done using equipment provided by the Biysk Regional Center for Shared Use of Scientific Equipment of the SB RAS (IPCET SB RAS, Biysk, Russia).

\section{Results and Discussion}

Biosynthesis of BNC

The scaled cultivation resulted in three pearl-white BNC sheets. Each sheet had dimensions same as the container, and the surface area of the sheet was $29,400 \mathrm{~cm}^{2}$. The sheets were visually even, nicely smooth to touch, and 0.6 to $0.7 \mathrm{~cm}$ thick. The basic indicators of the biosynthesis are summarized in Table 1.

Unique findings have been obtained in the course of this study: biosynthesis of BNC has been performed for the first time in a 260-L nutrient medium and BNC sheets have been produced, each weighing 16-17 kg. Besides, we demonstrated that two BNC sheets could be taken out of one volume of the nutrient medium. That is, the following situation was observed: at an initial glucose concentration of $20.1 \mathrm{~g} / \mathrm{L}$, the BNC sheet weighed $16.24 \mathrm{~kg}$ in 14 days of cultivation, the residual glucose concentration was $5.9 \mathrm{~g} / \mathrm{L}$. Upon further cultivation for another 14 days, one more BNC sheet was obtained, weighing $16.58 \mathrm{~kg}$, with the glucose concentration declined to $2 \mathrm{~g} / \mathrm{L}$. As was shown previously, a decrease in the initial glucose concentration below $20 \mathrm{~g} / \mathrm{L}$ adversely influences the BNC biosynthesis process [35]. How then the biosynthesis of the second BNC sheet can be explained if the initial glucose concentration was $5.9 \mathrm{~g} / \mathrm{L}$ ? As is well known, cellulose fibrils are synthesized by microbial producers through the formation of intermediates: glucose 6-phosphate is isomerized to glucose 1-phosphate which reacts with uridine triphosphate (UTP), forming uridine- $5^{\prime}$-diphosphate- $\alpha$-D-glucose (UDP-glucose). It is this compound that is attacked by 
the enzyme (cellulose synthase) that is responsible for transfer of glycosylic residues from UDF-glucose to the growing chain of $\beta$-D-1,4-glucan [22]. Apparently, the intermediates required for BNC synthesis are accumulated inside the microbial producer cells during the biosynthesis and gradually opt in the formation process of cellulosic fibers which are released outside from the cells. It is because of the accumulation of initial components of cellulose biosynthesis inside microorganisms that a few BNC sheets can be obtained in one nutrient medium, despite the fact that the amount of reducing sugars in the medium after the first removal of a BNC pellicle diminishes very considerably.

Table 1. Basic indicators of BNC biosynthesis.

\begin{tabular}{cccc}
\hline Characteristics & \multicolumn{3}{c}{ Sheet } \\
\cline { 2 - 4 } & $\mathbf{1}$ & $\mathbf{2 / 1}$ & $\mathbf{2 / 2}$ \\
\hline Initial volume of nutrient medium $(V, \mathrm{~L})$ & 260 & 260 & 229.52 \\
Residual volume of nutrient medium $(\mathrm{L})$ & 228.4 & 229.52 & 198.30 \\
pH of medium at the onset of biosynthesis & 3.8 & 3.9 & 2.7 \\
pH of medium upon completion of biosynthesis & 2.8 & 2.7 & 2.3 \\
Initial glucose concentration in nutrient medium $\left(C_{g}, \mathrm{~g} / \mathrm{L}\right)$ & 19.94 & 20.10 & 5.90 \\
Residual glucose concentration in nutrient medium $(\mathrm{g} / \mathrm{L})$ & 6.80 & 5.90 & 2.00 \\
Weight of BNC sheet $(\mathrm{kg})$ & 17.04 & 16.24 & 16.58 \\
Moisture of BNC sheet $(\%)$ & 98.99 & 99.01 & 99.00 \\
BNC yield $(\eta, \%)$ & 3.69 & 3.45 & 13.60
\end{tabular}

The second explanation of the observed phenomenon of the synthesis of the second BNC sheet in the nutrient medium with a low glucose concentration is that the Medusomyces gisevii symbiotic culture develops its own metabolic pathway during its evolution, in which all the nutrients required for the normal functioning of the symbiosis are synthesized by the symbiotic culture itself. This culture is capable of switching from one substrate to another and utilizing its own metabolic products as substrates. The culture is known to be capable of utilizing a number of organic acids such as acetic, gluconic, succinic, lactic, malic and glycerol, which are its metabolic products [40].

Compared to the previous findings on biosynthesis of $\mathrm{BNC}$ in a $72 \mathrm{~L}$ nutrient medium [38] for 7 days of cultivation, the yield declined by 1.4 times (from $5.20 \%$ to $3.45-3.69 \%$ ) in case the sheet was taken out once, and the yield increased by 1.3 times from $5.20 \%$ to $6.98 \%$ in case two BNC sheets were removed from one volume of the nutrient medium $(260 \mathrm{~L})$. If the yields of the BNC sheets are compared within the given experiment, it can be noted that the overall yield of $\mathrm{BNC}$ in the second experiment is almost twice that in the first experiment: $6.98 \%$ (Sheet $2 / 1+$ Sheet $2 / 2$ ) versus $3.69 \%$ (Sheet 1 ). That said, the objective of producing a strong BNC sheet with dimensions allowing an adult to be wrapped therein has been achieved. A photo of an adult wrapped in the BNC sheet is depicted in Figure 3.

Molina-Ramírez et al. [25,26] described a 40-fold scale-up starting from a $90-\mathrm{cm}^{3}$ glass vessel to a plastic container $62.5 \mathrm{~cm}$ long, $29 \mathrm{~cm}$ wide and $18.5 \mathrm{~cm}$ high; the culture medium volume was raised from $45 \mathrm{~cm}^{3}$ to $1800 \mathrm{~cm}^{3}$. The results were obtained using an alternative nutrient medium, i.e., overripe banana, and a Komagataeibacter medellinensis strain. The yield (in total volume, $\mathrm{g} / \mathrm{L}$ ) was 5 in the first case and 4 in the second; the dry weight $(\mathrm{g})$ was 0.46 and 16, respectively. That said, those authors concluded that the quantity of the BNC obtained in the scale-up was $16 \mathrm{~g}, 3378 \%$ greater than that obtained in the glass vessel under optimized conditions. Following this logic, the quantity of the BNC obtained in the scale-up in our case was $16.24-17.04 \mathrm{~kg}$, which is $173,504-182,051 \%$ greater than that obtained in the 0.1-L nutrient medium.

Figure 4 illustrates SEM images of the BNC sheets. As can be seen in the images, all three sheets exhibit a representative architecture of cellulosic fibers: each BNC sheet represents a bundle of cellulosic nanofibrils as clusters of stretched cellulosic chains that 
form a spatial 3D structure which relates to individual and highly important characteristics of BNC $[1,41]$.
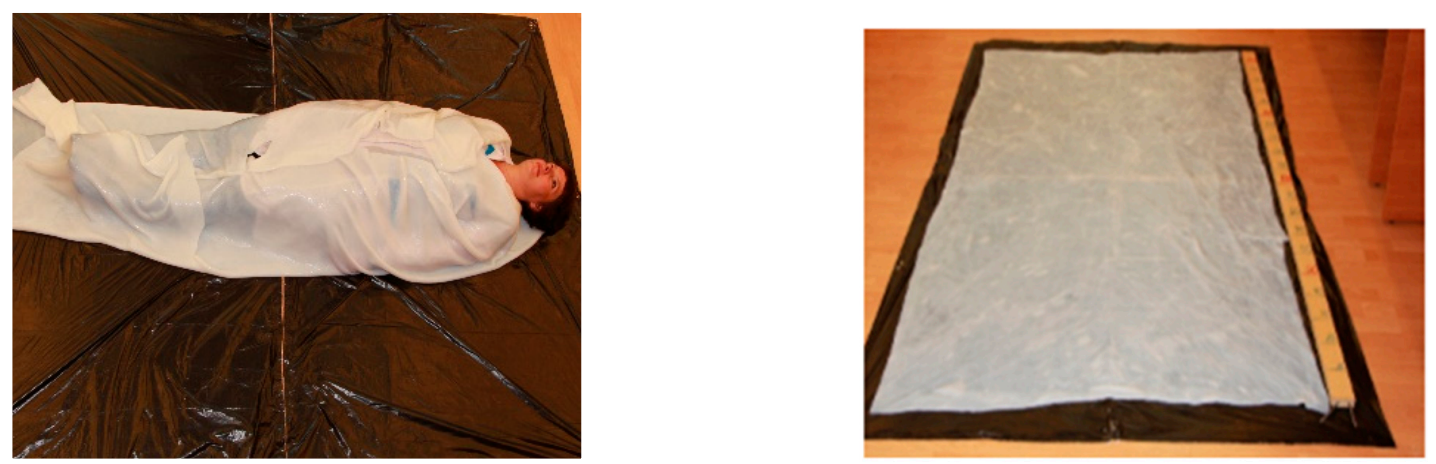

Figure 3. An adult wrapped in the BNC sheet (the ruler is $2 \mathrm{~m}$ long).

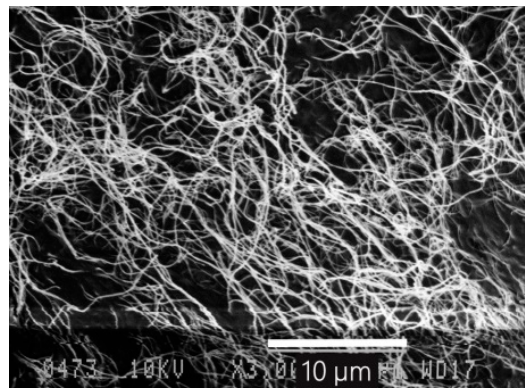

(a)

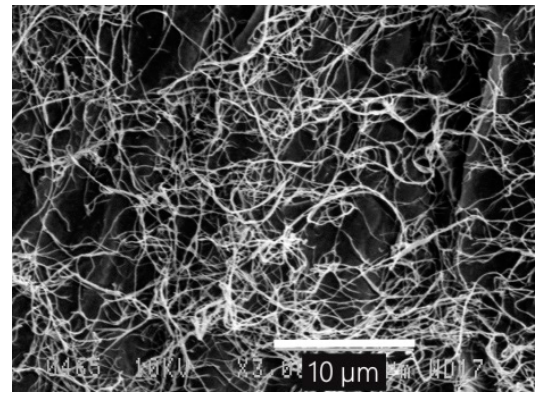

(b)

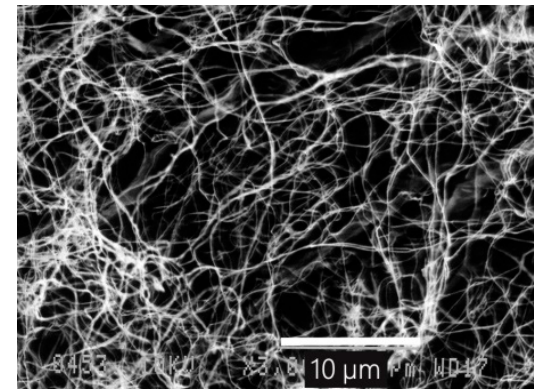

(c)

Figure 4. SEM images of BNC: (a) Sheet 1, (b) Sheet 2/1 and (c) Sheet $2 / 2$ at a zoom of $\times 3000$.

Table 2 lists cellulose degrees of polymerization, strength behavior and TGA data for BNC. For the all three BNC sheets, the degree of polymerization had high values ranging from 4900 to 5200. The elastic modulus was also high, between 9180 and $9687 \mathrm{MPa}$, in all the three cases. It is noteworthy that for the second removed Sheet $2 / 2$, the degree of polymerization was $12 \%$ greater and the elastic modulus was $5.5 \%$ higher than for the first removed Sheet 2/1, with the weights of the sheets being in fact identical. This is a very optimistic fact for industrial cultivation: two BNC sheets can be taken out of the single nutrient medium without impairment of BNC quality.

Table 2. Cellulose degree of polymerization, strength characteristics and TGA data for BNC.

\begin{tabular}{|c|c|c|c|}
\hline \multirow{2}{*}{ Characteristic } & \multicolumn{3}{|c|}{ Sheet } \\
\hline & 1 & $2 / 1$ & $2 / 2$ \\
\hline Degree of polymerization & 4920 & 4900 & 5500 \\
\hline \multicolumn{4}{|c|}{ Strength behavior } \\
\hline Conventional yield limit, $\left(\sigma_{\mathrm{sx}}, \mathrm{MPa}\right)$ & 54.55 & 52.31 & 50.49 \\
\hline Strength at break $\left(\sigma_{\mathrm{r}}, \mathrm{MPa}\right)$ & 160.41 & 155.32 & 151.12 \\
\hline Relative elongation at break $\left(\varepsilon_{\tau}, \%\right)$ & 2.94 & 2.71 & 2.60 \\
\hline Relative elongation at yield $\left(\varepsilon_{\mathrm{Sx}}, \%\right)$ & 0.59 & 0.54 & 0.55 \\
\hline Elastic modulus (E, $\mathrm{MPa})$ & 9246 & 9180 & 9687 \\
\hline \multicolumn{4}{|c|}{ Summary TGA data } \\
\hline Sample weight variation in the first stage, $\%$ & 2.56 & 3.37 & 2.43 \\
\hline $\begin{array}{l}\text { Sample weight variation in the second stage (in a } \\
\text { range of sample decomposition), } \%\end{array}$ & 62.54 & 61.25 & 62.11 \\
\hline Onset temperature of decomposition, ${ }^{\circ} \mathrm{C}$ & 316.20 & 315.71 & 316.54 \\
\hline Sample weight variation in the third stage, $\%$ & 10.78 & 10.11 & 10.22 \\
\hline Residue, \% & 24.12 & 25.27 & 25.24 \\
\hline
\end{tabular}


By evaluating the mechanical characteristics of the BNC sheets and comparing them with the previous data for the same cultivation conditions, nutrient medium composition and the microbial producer used [28], it can be noted that when the biosynthesis process of BNC is scaled up by 2600 times, the elastic modulus rises tenfold (for samples obtained in a 0.1-L nutrient medium, this parameter was $933 \mathrm{MPa}$ ), while the degree of polymerization increases 2.5-fold (2200 versus 5500). Thus, when the BNC biosynthesis is scaled up, the strength of the samples and the degree of polymerization of cellulosic fibers increase. These findings are of scientific interest because Molina-Ramírez et al. [31] reported a decrease in elastic modulus from $1149.84 \mathrm{MPa}$ to $569.04 \mathrm{MPa}$ when they scaled up biosynthesis by 44 times from $90 \mathrm{~mL}$ to $4 \mathrm{~L}$ using an alternative medium-overripe Banana juice-and a Komagataeibacter medellinensis strain. In this case, the elastic modulus was noticed to decline twofold, whereas the decomposition temperature and crystallinity index were approximately equal $[25,26]$.

The TGA data listed in Table 2 are given for all the three stages representative of BNC $[42,43]$. The first stage is associated with evaporation of highly volatile components (water) of the sample over a temperature range from $25^{\circ} \mathrm{C}$ to $150^{\circ} \mathrm{C}$. At the second stage, the sample undergoes a maximum weight loss, which is due BNC being decomposed by pyrolysis over a temperature range between $150{ }^{\circ} \mathrm{C}$ and $400{ }^{\circ} \mathrm{C}$. The third stage shows re-decomposition of the material, which is ascribed to degradation of the polymeric chains and the six-membered cyclic structure of pyran [43], and this stage is observed over a temperature range from $400{ }^{\circ} \mathrm{C}$ to $600{ }^{\circ} \mathrm{C}$. The TGA data demonstrate very close values of decomposition temperature of the samples (315.71-316.54 ${ }^{\circ} \mathrm{C}$;) and the residues after decomposition (24.12-25.27\%), indicating that the samples are identical in structure and have a high purity.

Figure 5 depicts an infrared spectrogram of the BNC sheets. The obtained IR spectra of all the three BNC sheets were almost identical and demonstrated a pattern typical of cellulose: absorption bands at $3363 \mathrm{~cm}^{-1}$ were attributed to stretch vibrations of $\mathrm{OH}$ groups and absorption bands at $2895 \mathrm{~cm}^{-1}$ were due to stretch vibrations of $\mathrm{CH}_{2}$ and $\mathrm{CH}$ groups. Absorptions bands at $1634 \mathrm{~cm}^{-1}$ were for bending vibrations of $\mathrm{OH}$ groups of strongly bound water. Absorption bands near 1430-1370 $\mathrm{cm}^{-1}$ suggested bending vibrations of $\mathrm{CH}_{2}$ and $\mathrm{CH}$ groups. Absorption bands near $1340-1320 \mathrm{~cm}^{-1}$ indicated bending vibrations of the primary $\mathrm{OH}$ alcohol group, those near $1290-1240 \mathrm{~cm}^{-1}$ stood for bending vibrations of $\mathrm{CH}_{2}$ alcohol group, and those near $1160-1040 \mathrm{~cm}^{-1}$ referred to stretch vibrations of C-O-C and C-O alcohol groups. Absorption bands at $899 \mathrm{~cm}^{-1}$ corroborated the presence of $\beta-1,4$ glycosidic bonds of glucose $[44,45]$.

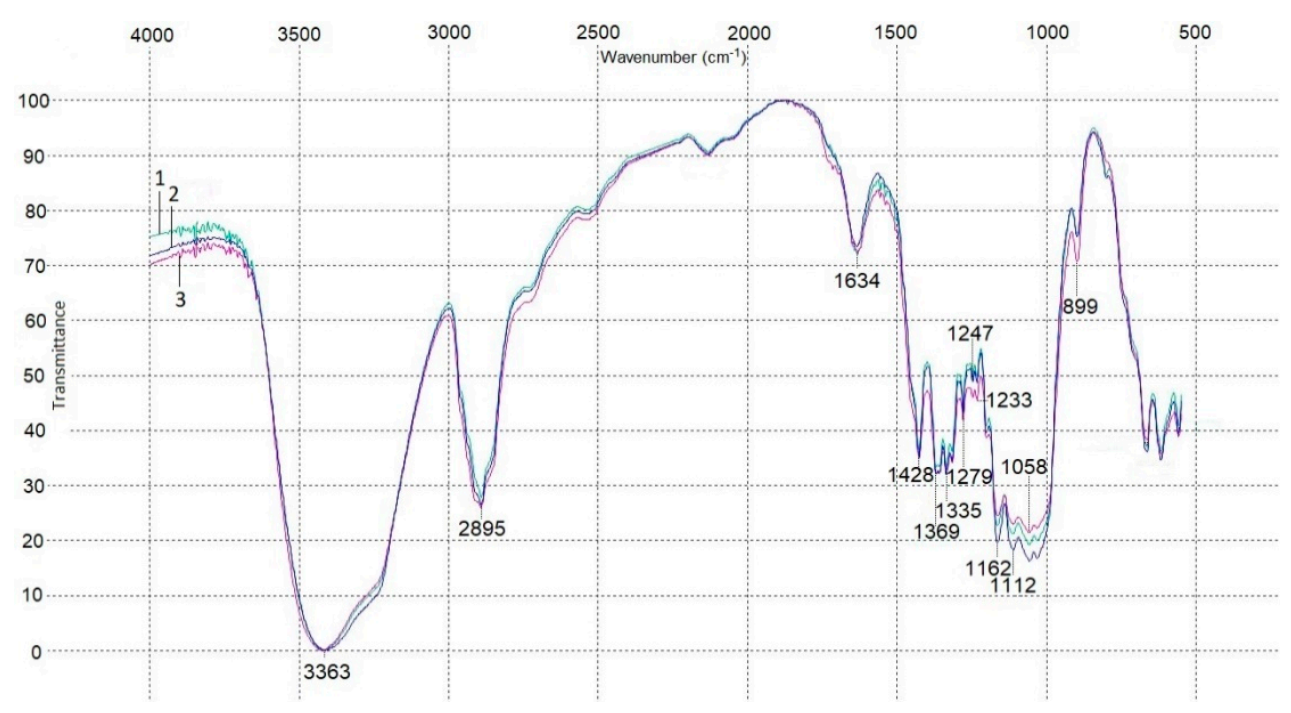

Figure 5. IR spectroscopy data for BNC sheets: 1 - Sheet $1 ; 2$ - Sheet 2/1; and 3-Sheet 2/2. 


\section{Conclusions}

The scale-up of static biosynthesis of BNC in a semisynthetic nutrient medium in a 441-L metal container using the Medusomyces gisevii Sa-12 symbiotic culture afforded three strong BNC sheets, each having an area of $29,400 \mathrm{~cm}^{2}$ and a weight ranging from 16.24 to $17.04 \mathrm{~kg}$, in which an adult having burns or vast wounds can easily be wrapped. This finding is pioneer among the examples of static culture on account of the maximum nutrient medium volume of $260 \mathrm{~L}$ and the high cellulose degree of polymerization and strength of the resultant sheets. When the biosynthesis was scaled up from $0.1 \mathrm{~L}$ to $260 \mathrm{~L}$ of the nutrient medium, the elastic modulus of the BNC samples increased tenfold and the degree of polymerization by 2.5 times, which is attributed particularly to the symbiotic culture used. Besides, it was demonstrated that at least two scaled BNC sheets could be taken out of one volume of the nutrient medium without reduced yield and quality of BNC.

Author Contributions: Conceptualization, V.V.B.; methodology, N.A.S.; validation, E.A.S., G.F.M., Y.A.G., E.I.K.; formal analysis, E.A.S.; investigation, N.V.B., A.E.S., A.I.S., P.S.K.; writing-original draft preparation, N.A.S.; writing-review and editing, V.V.B., E.A.S.; supervision, G.V.S. All authors have read and agreed to the published version of the manuscript.

Funding: This research was funded by the Russian Science Foundation (grant No. 17-19-01054).

Institutional Review Board Statement: Not applicable, as the study did not involve humans or animals.

Informed Consent Statement: Not applicable, as the study did not involve humans.

Data Availability Statement: The raw/processed data required to reproduce these findings are available from the author upon request.

Conflicts of Interest: The authors declare no conflict of interest.

\section{References}

1. Gama, M.; Dourado, F.; Bielecki, S. Bacterial Nanocellulose: From Biotechnology to Bio-Economy; Elsevier: Cambridge, MA, USA, 2016; p. 260.

2. Azeredo, H.M.C.; Barud, H.; Farinas, C.S.; Vasconcellos, V.M.; Claro, A.M. Bacterial cellulose as a raw material for food and food packaging applications. Front. Sustain. Food Syst. 2019, 7, 3. [CrossRef]

3. Gorgieva, S.; Trček, J. Bacterial cellulose: Production, modification and perspectives in biomedical applications. Nanomaterials 2019, 9, 1352. [CrossRef] [PubMed]

4. El-Hoseny, S.M.; Basmaji, P.; de Olyveira, G.M.; Costa, L.M.M.; Alwahedi, A.M.; da Costa Oliveira, J.D.; Francozo, G.B. Natural ECM-bacterial cellulose wound healing-Dubai study. J. Biomater. Nanobiotechnol. 2015, 6, 237. [CrossRef]

5. Sharma, C.; Bhardwaj, N.K. Bacterial nanocellulose: Present status, biomedical applications and future perspectives. Mater. Sci. Eng. C 2019, 104, 109963. [CrossRef] [PubMed]

6. Svensson, A.; Nicklasson, E.; Harrah, T.; Panilaitis, B.; Kaplan, D.L.; Brittberg, M.; Gatenholm, P. Bacterial cellulose as a potential scaffold for tissue engineering of cartilage. Biomaterials 2005, 26, 419-431. [CrossRef]

7. Wu, J.; Zheng, Y.; Yang, Z.; Lin, Q.; Qiao, K.; Chen, X.; Peng, Y. Influence of dialdehyde bacterial cellulose with the nonlinear elasticity and topology structure of ECM on cell adhesion and proliferation. RSC Adv. 2014, 4, 3998-4009. [CrossRef]

8. Helenius, G.; Backdahl, H.; Bodin, A.; Nannmark, U.; Gatenholm, P.; Risberg, B. In vivo biocompatibility of bacterial cellulose. J. Biomed. Mater. Res. A 2006, 76, 431-438. [CrossRef]

9. Torres, G.F.; Commeaux, S.; Troncoso, P.O. Biocompatibility of bacterial cellulose based biomaterials. J. Funct. Biomater. 2012, 3 , 864-878. [CrossRef] [PubMed]

10. Kaewnopparat, S.; Sansernluk, K.; Faroongsarng, D. Behavior of freezable bound water in the bacterial cellulose produced by Acetobacter xylinum: An approach using thermoporosimetry. AAPS PharmSciTech 2008, 9, 701-707. [CrossRef]

11. Lin, S.-B.; Hsu, C.-P.; Chen, L.-C.; Chen, H.-H. Adding enzymatically modified gelatin to enhance the rehydration abilities and mechanical properties of bacterial cellulose. Food Hydrocoll. 2009, 23, 2195-2203. [CrossRef]

12. Schrecker, S.T.; Gostomski, P.A. Determining the water holding capacity of microbial cellulose. Biotechnol. Lett. 2005, 27, 1435-1438. [CrossRef]

13. Ul-Islam, M.; Khan, T.; Park, J.K. Water holding and release properties of bacterial cellulose obtained by in situ and ex situ modification. Carbohydr. Polym. 2012, 88, 596-603. [CrossRef]

14. Hu, Y.; Catchmark, J.M. In vitro biodegradability and mechanical properties of bioabsorbable bacterial cellulose incorporating cellulases. Acta Biomater. 2011, 7, 2835-2845. [CrossRef] [PubMed] 
15. Laçin, N.T. Development of biodegradable antibacterial cellulose based hydrogel membranes for wound healing. Int. J. Biol. Macromol. 2014, 67, 22-27. [CrossRef]

16. Ring, D.F.; Nashed, W.; Dow, T. Liquid Loaded Pad for Medical Applications. U.S. Patent No US4588400A, 13 May 1986.

17. Ring, D.F.; Nashed, W.; Dow, T. Microbial Polysaccharide Articles and Methods of Production. U.S Patent No US4655758A, 7 April 1987.

18. United States Congress. Biopolymers: Making Materials Nature's Way; U.S. Congress: Washington, DC, USA, 1993.

19. Krystynowicz, A. Method of Bacterial Cellulose Production, Sposob Wytwarzania Celulozy Bakteryjnej. World Intellectual Property Organisation Poland. Patent PL WO2005003366A1, 13 January 2005.

20. Chen, G.; Wu, G.; Alriksson, B.; Chen, L.; Wang, W.; Jönsson, L.J.; Hong, F.F. Scale-Up of production of bacterial nanocellulose using submerged cultivation. J. Chem. Technol. Biotechnol. 2018, 93, 3418-3427. [CrossRef]

21. Campano, C.; Balea, A.; Blanco, A.; Negro, C. Enhancement of the fermentation process and properties of bacterial cellulose: A review. Cellulose 2015, 23, 57-91. [CrossRef]

22. Römling, U.; Galperin, M.Y. Bacterial cellulose biosynthesis: Diversity of operons, subunits, products, and functions. Trends Microbiol. 2015, 23, 545-557. [CrossRef]

23. Wang, J.; Tavakoli, J.; Tang, Y. Bacterial cellulose production, properties and applications with different culture methods-A review. Carbohydr. Polym. 2019, 2019, 63-76. [CrossRef]

24. Hussain, Z.; Sajjad, W.; Khan, T.; Wahid, F. Production of bacterial cellulose from industrial wastes: A review. Cellulose 2019, 26, 2895-2911. [CrossRef]

25. Molina-Ramírez, C.; Cañas-Gutiérrez, A.; Castro, C.; Zuluaga, R.; Gañán, P. Effect of production process scale-up on the characteristics and properties of bacterial nanocellulose obtained from overripe Banana culture medium. Carbohydr. Polym. 2020, 240, 116341. [CrossRef]

26. Molina-Ramírez, C.; Álvarez, J.; Zuluaga, R.; Castro, C.; Gañán, P. A novel approach using conventional methodologies to scale up BNC production using Komagataeibacter medellinensis and rotten banana waste as alternative. Processes 2020, 8, 1469. [CrossRef]

27. Skiba, E.A.; Budaeva, V.V.; Ovchinnikova, E.V.; Gladysheva, E.K.; Kashcheyeva, E.I.; Pavlov, I.N.; Sakovich, G.V. A technology for pilot production of bacterial cellulose from oat hulls. Chem. Eng. Technol. 2020, 383, 123128. [CrossRef]

28. Skiba, E.A.; Gladysheva, E.K.; Golubev, D.S.; Budaeva, V.V.; Aleshina, L.A.; Sakovich, G.V. Self-Standardization of quality of bacterial cellulose produced by Medusomyces gisevii in nutrient media derived from Miscanthus biomass. Carbohydr. Polym. 2021, 252, 117178. [CrossRef] [PubMed]

29. Velásquez-Riaño, M.; Bojacá, V. Production of bacterial cellulose from alternative low-cost substrates. Cellulose 2017, 24, 2677-2698. [CrossRef]

30. Choi, C.N.; Song, H.J.; Kim, M.J.; Chang, M.H.; Kim, S.J. Properties of bacterial cellulose produced in a pilot-scale spherical type bubble column bioreactor. Korean J. Chem. Eng. 2009, 26, 136-140. [CrossRef]

31. Reiniati, I. Bacterial Cellulose Nanocrystals: Production and Application. Electronic Thesis and Dissertation Repository. 2017, p. 4826. Available online: https:/ /ir.lib.uwo.ca/etd/4826 (accessed on 9 June 2021).

32. Wu, S.-C.; Li, M.-H. Production of bacterial cellulose membranes in a modified airlift bioreactor by Gluconacetobacter xylinus. J. Biosci. Bioeng. 2015, 120, 444-449. [CrossRef]

33. Lee, K.-Y.; Buldum, G.; Mantalaris, A.; Bismarck, A. More than meets the eye in bacterial cellulose: Biosynthesis, bioprocessing, and applications in advanced fiber composites. Macromol. Biosci. 2014, 14, 10-32. [CrossRef]

34. Klemm, D.; Cranston, E.D.; Fischer, D.; Gama, M.; Kedzior, S.A.; Kralisch, D.; Kramer, F.; Kondo, T.; Lindström, T.; Nietzsche, S.; et al. Nanocellulose as a natural source for groundbreaking applications in materials science: Today's state. Mater. Today 2018, 21, 720-748. [CrossRef]

35. Gladysheva, E.K.; Skiba, E.A.; Zolotukhin, V.N.; Sakovich, G.V. Study of the conditions for the biosynthesis of bacterial cellulose by the producer Medusomyces gisevii Sa-12. Appl. Biochem. Microbiol. 2018, 54, 179-187. [CrossRef]

36. Miller, G.L. Use of dinitrosalicylic acid reagent for determination of reducing sugar. Anal. Chem. 1959, 31, 426-428. [CrossRef]

37. Gromovykh, T.I.; Lutcenko, S.V.; Feldman, N.B.; Kashirin, V.V.; Sadykova, V.S.; Dmitrenok, A.S.; Danilchuk, T.N. Bacterial cellulose synthesized by Gluconacetobacter hansenii for medical applications. Appl. Biochem. Microbiol. 2017, 53, 60-67. [CrossRef]

38. Budaeva, V.V.; Gismatulina, Y.A.; Mironova, G.F.; Skiba, E.A.; Gladysheva, E.K.; Kashcheyeva, E.I.; Baibakova, O.V.; Korchagina, A.A.; Shavyrkina, N.A.; Golubev, D.S.; et al. Bacterial nanocellulose nitrates. Nanomaterials 2019, 9, 1694. [CrossRef] [PubMed]

39. Bogolitsyn, K.; Parshina, A.; Aleshina, L. Structural features of brown algae cellulose. Cellulose 2020, 27, 1-14. [CrossRef]

40. Yurkevich, D.I.; Kutyshenko, V.P. Medusomyces (Tea fungus): A scientific history, composition, features of physiology and metabolism. Biophysics 2002, 47, 1035-1048.

41. Gromovykh, T.I.; Pigaleva, M.A.; Gallyamov, M.O.; Ivanenko, I.P.; Ozerova, K.E.; Kharitonova, E.P.; Bahman, M.; Feldman, N.B.; Lutsenko, S.V.; Kiselyova, O.I. Structural organization of bacterial cellulose: The origin of anisotropy and layered structures. Carbohydr. Polym. 2020, 237, 116140. [CrossRef] [PubMed]

42. Cheng, K.C.; Catchmark, J.M.; Demirci, A. Enhanced production of bacterial cellulose by using a biofilm reactor and its material property analysis. J. Biol. Eng. 2009, 3, 12. [CrossRef]

43. Torgbo, S.; Sukyai, P. Biodegradation and thermal stability of bacterial cellulose as biomaterial: The relevance in biomedical applications. Polym. Degrad. Stab. 2020, 179, 109232. [CrossRef] 
44. Yin, X.; Zhang, X.; Yang, J.; Lin, Q.; Wang, J.; Zhu, Q. Comparison of succinylation methods for bacterial cellulose and adsorption capacities of bacterial cellulose derivatives for $\mathrm{Cu}^{2+}$ ion. Polym. Bull. 2011, 67, 401-412. [CrossRef]

45. Goh, W.N.; Rosma, A.; Kaur, B.; Fazilah, A.; Karim, A.A.; Rajeev, B. Microstructure and physical properties of microbial cellulose produced during fermentation of black tea broth (Kombucha). II. Int. Food Res. J. 2012, 19, 153-158. 